Article

\title{
Antimicrobial Properties of Lyophilized Extracts of Olive Fruit, Pomegranate and Orange Peel Extracts against Foodborne Pathogenic and Spoilage Bacteria and Fungi In Vitro and in Food Matrices
}

\author{
Chrysanthi Mitsagga ${ }^{1}$, Konstantinos Petrotos ${ }^{2}$ and Ioannis Giavasis ${ }^{1, *}$ (D)
}

1 Department of Food Science and Human Nutrition, School of Agricultural Sciences, Karditsa Campus, University of Thessaly, Terma Odou N. Temponera, 43100 Karditsa, Greece; cmitsanga@uth.gr

2 Department of Agrotechnology, School of Agricultural Sciences, Geopolis Campus, University of Thessaly, Periferiaki Odos Larisas Trikalon, 41500 Larisa, Greece; petrotos@uth.gr

* Correspondence: igiavasis@uth.gr; Tel.: +30-2441-064785 or +30-6977-455433

check for updates

Citation: Mitsagga, C.; Petrotos, K.; Giavasis, I. Antimicrobial Properties of Lyophilized Extracts of Olive Fruit, Pomegranate and Orange Peel Extracts against Foodborne Pathogenic and Spoilage Bacteria and Fungi In Vitro and in Food Matrices. Molecules 2021, 26, 7038. https:// doi.org/10.3390/molecules26227038

Academic Editor: Luisa Tesoriere

Received: 6 October 2021

Accepted: 10 November 2021

Published: 21 November 2021

Publisher's Note: MDPI stays neutral with regard to jurisdictional claims in published maps and institutional affiliations.

Copyright: (c) 2021 by the authors. Licensee MDPI, Basel, Switzerland. This article is an open access article distributed under the terms and conditions of the Creative Commons Attribution (CC BY) license (https:// creativecommons.org/licenses/by/ $4.0 /)$.

\begin{abstract}
Several novel antimicrobials with different concentrations of olive, pomegranate, and orange fruit pulp extracts were produced from agricultural byproducts and, after lyophilization, their antimicrobial activity and potential synergistic effects were evaluated in vitro and in food samples against foodborne pathogenic and spoilage bacteria and fungi. The Minimum Inhibitory of the tested bacteria was $7.5 \%$ or $10 \%$, while fungi were inhibited at a concentration of $10 \%$ or above. The optical density of bacterial and yeast cultures was reduced to a different extent with all tested antimicrobial powders, compared to a control without antimicrobials, and mycelium growth of fungi was also restricted with extracts containing at least $90 \%$ olive extract. In food samples with inoculated pathogens and spoilage bacteria and fungi, the $100 \%$ olive extract was most inhibitory against E. coli, S. typhimurium, and L. monocytogenes in fresh burger and cheese spread samples (by 0.6 to $1.8 \log \mathrm{cfu} / \mathrm{g}$ ), except that $S$. typhimurium was better inhibited by a $90 \%$ olive and $10 \%$ pomegranate extract in burgers. The latter extract was also the most effective in controlling the growth of inoculated fungi (Aspergillus niger, Penicillium italicum, Rhodotorula mucilaginosa) in both yogurt and tomato juice samples, where it reduced fungal growth by $1-2.2 \log \mathrm{cfu} / \mathrm{g}$ at the end of storage period. The results demonstrate that these novel encapsulated extracts could serve as natural antimicrobials of wide spectrum, in order to replace synthetic preservatives in foods and cosmetics.
\end{abstract}

Keywords: olive fruit extract; pomegranate pulp extract; orange pulp extract; novel antimicrobials; natural preservatives; foodborne pathogens; spoilage microorganism; byproduct utilization

\section{Introduction}

Agroindustrial waste are posing a serious environmental and economic problem worldwide, since one third of the food produced for human consumption is disposed of as waste according to FAO, leading to environmental pollution, depletion of natural resources and compromised food security [1]. Therefore, UN countries have committed to reduce (by 50\%) the food waste generated per capita at the retail and consumer level and decrease substantially the agro-industrial waste along the food supply chain by 2030, within the United Nations Sustainable Development Goal 12.3 [1]. For this reason, in the last decades the food industry has been seeking ways to utilize agricultural waste in order to tackle waste management and also produce novel products of added value. Notably, the utilized food byproducts, especially fruit and vegetable by-products, often consist of valuable components [2] such as phenols, flavonoids, pigments, and organic acids, which can be used in food and feed as natural antioxidants and/or antimicrobials [3-5], or in phytoprotection [5-7] and in cosmetics and pharmaceuticals [8], potentially replacing synthetic chemical preservatives. Our research has focused on the utilization of olive 
mill waste, orange peel, and pomegranate peel waste and their potential application as natural antimicrobial substances in vitro against important food pathogens and spoilage microorganisms and in the formulation of natural substances that can replace chemical additives in food matrices, in accordance with consumers' demand for "green label" foods. Olive mill wastewater is the liquid by-product of the olive oil production industry. According to Chowdhury et al. [9], olive mill waste water (OMW) has a high organic load (BOD 89-100 $\mathrm{g} \mathrm{L}^{-1}$, COD 80-200 $\mathrm{g} \mathrm{L}^{-1}$ ), which is characterized by high phytotoxicity. The dark color of OMW is mainly caused by the abundant phenolic compounds, which are also responsible for the phytotoxicity [10]. However, these phenolic compounds, or polyphenols of OMW, also have strong antioxidant and antimicrobial properties, especially after encapsulation of the olive extracts [11,12].

Orange fruit pulp and peels represent a large amount of the total worldwide production of $>73$ million tons of orange fruits [5] and their disposal is problematic especially in the orange juice industry. Interestingly, these byproducts of juice production are rich in phenols, flavonoids, flavone glycosides, organic acids, as well essential oils, which are reported to exert antimicrobial activity against several bacterial pathogens [13-15].

Pomegranate waste (peel and seeds) are produced in a similar manner during the processing of pomegranates (Punica granatum L.) for the production of juice. Pomegranate fruit byproducts and extracts thereof have high concentrations of polyphenols and tannins, thus demonstrating strong antioxidant and antimicrobial activity against several pathogens and spoilage microorganisms, which depends partly on the extraction method and the part of the fruit that is used [16-19]. In fact, peels appear to be richer in phenols and antioxidant compounds compared to pomegranate pulp [17].

After appropriate membrane filtration, purification, and encapsulation of plant extracts without use of chemical solvents (i.e., consecutive dialfitration with the addition of water, ultrafiltration to remove high molecular weight solids and reverse osmosis to remove salts, followed by encapsulation in maltodextrin via freeze drying), a polyphenolrich extract can be obtained from OMW [20], which has been effective in controlling the growth of several fungal and bacterial pathogens [5,12], as well as enhancing the growth of beneficial lactic acid bacteria when used at low concentrations [21]. Using an adequate concentration of these natural extracts is crucial in exhibiting inhibitory effects against microorganisms, but their dark color and intense taste can be deterrent in food applications; this can be alleviated via encapsulation in edible carriers such as maltodextrin [21].

In the present study, polyphenol-rich extracts of OMW, orange and pomegranate peel were combined in different ratios and encapsulated into lyophilized powders, with the scope of utilizing simultaneously the main byproducts of three large agricultural industries and also enhancing the already documented antimicrobial activity of encapsulated olive polyphenols [5,12], by a potential synergistic affect with pomegranate and/or orange pulp extracts, which can also be rich phenols and flavonoids, especially after appropriate optimization of extraction conditions [22,23].

\section{Results}

\subsection{Measurement of the Total Phenols, Flavonoids and $p H$ of Selected Lyophilized Antimicrobial Powders}

The coding of all antimicrobial extracts and the composition of each encapsulated extract are explained in detail in Section 4.1 (Materials and Methods).

The measurements of phenols and flavonoids concentration of the selected antimicrobial powders are shown in Table 1. Extract 100/0/0 was richest in phenols $(47.86 \mathrm{~g} / \mathrm{Kg})$ expressed as equivalents of gallic acid, while extract $80 / 20 / 0$ had the highest content of flavonoids, expressed as equivalents of quercetin. All extracts had a slightly acidic $\mathrm{pH}$ around 5 , among which the extract $80 / 0 / 20$ had the lowest $\mathrm{pH}$. 
Table 1. Concentration of total phenols, flavonoids, and $\mathrm{pH}$ values of the selected antimicrobial powders.

\begin{tabular}{cccc}
\hline Powder Code No. & $\begin{array}{c}\text { Phenols } \\
\text { g/Kg Powder }\end{array}$ & $\begin{array}{c}\text { Flavonoids } \\
\text { g/Kg Powder }\end{array}$ & $\begin{array}{c}\text { pH } \\
\text { (of 10\% Water Solution) }\end{array}$ \\
\hline $100 / 0 / 0$ & 47.86 & 51.15 & 5.08 \\
\hline $90 / 5 / 5$ & 41.88 & 54.60 & 5.07 \\
\hline $90 / 10 / 0$ & 43.38 & 59.58 & 5.10 \\
\hline $90 / 0 / 10$ & 38.76 & 55.80 & 5.05 \\
\hline $80 / 10 / 10$ & 42.89 & 57.50 & 5.03 \\
\hline $80 / 20 / 0$ & 40.05 & 65.50 & 5.07 \\
\hline $80 / 0 / 20$ & 36.25 & 51.80 & 5.01 \\
\hline
\end{tabular}

It seems that a very high content of olive extract $(100 \%)$ contributes to a higher concentration of phenols, but a relatively modest content of flavonoids, while a high ratio of pomegranate extract $(20 \%)$ leads to a high content of flavonoids, but also contributes to the phenol concentration to some extent. A relatively high content $(20 \%)$ of orange extract may reduce the $\mathrm{pH}$ of the extract, but results in low phenol content and is not very rich in flavonoids, either.

\subsection{Minimum Inhibitory Concentration (MIC) and Minimum Lethal Concentration (MLC)}

Table 2 depicts the Minimum Inhibitory Concentration (MIC) of different cultures of foodborne pathogenic bacteria and pathogenic or spoilage fungi.

Table 2. Minimum inhibitory concentration of selected antimicrobial powders against several foodborne bacteria and fungi.

\begin{tabular}{|c|c|c|c|c|c|c|c|c|c|c|c|c|}
\hline 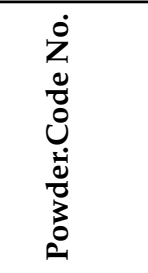 & 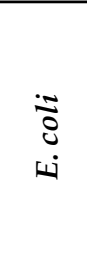 & 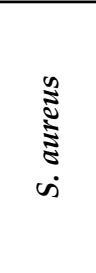 & 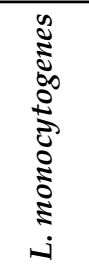 & 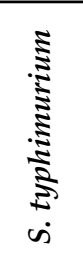 & 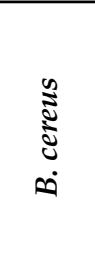 & $\frac{\mathfrak{Z}}{\mathfrak{D}}$ & 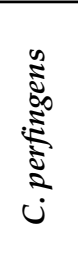 & 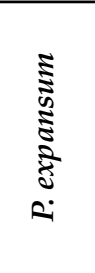 & 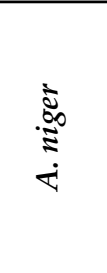 & 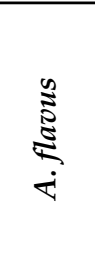 & 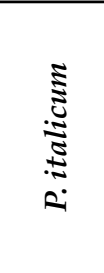 & 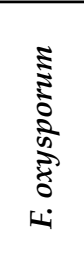 \\
\hline $100 / 0 / 0$ & $10 \%$ & $10 \%$ & $7.5 \%$ & $7.5 \%$ & $7.5 \%$ & $7.5 \%$ & $10 \%$ & $>10 \%$ & $>10 \%$ & $>10 \%$ & $>10 \%$ & $7.5 \%$ \\
\hline $90 / 5 / 5$ & $10 \%$ & $7.5 \%$ & $7.5 \%$ & $7.5 \%$ & $7.5 \%$ & $7.5 \%$ & $10 \%$ & $>10 \%$ & $>10 \%$ & $>10 \%$ & $>10 \%$ & $7.5 \%$ \\
\hline $90 / 10 / 0$ & $7.5 \%$ & $7.5 \%$ & $7.5 \%$ & $7.5 \%$ & $7.5 \%$ & $7.5 \%$ & $10 \%$ & $>10 \%$ & $>10 \%$ & $>10 \%$ & $>10 \%$ & $10 \%$ \\
\hline $90 / 0 / 10$ & $10 \%$ & $10 \%$ & $7.5 \%$ & $7.5 \%$ & $7.5 \%$ & $10 \%$ & $10 \%$ & $>10 \%$ & $>10 \%$ & $>10 \%$ & $>10 \%$ & $10 \%$ \\
\hline $80 / 10 / 10$ & $10 \%$ & $7.5 \%$ & $7.5 \%$ & $7.5 \%$ & $7.5 \%$ & $7.5 \%$ & $10 \%$ & $>10 \%$ & $>10 \%$ & $>10 \%$ & $>10 \%$ & $7.5 \%$ \\
\hline $80 / 20 / 0$ & $10 \%$ & $7.5 \%$ & $7.5 \%$ & $7.5 \%$ & $7.5 \%$ & $7.5 \%$ & $10 \%$ & $>10 \%$ & $>10 \%$ & $>10 \%$ & $>10 \%$ & $10 \%$ \\
\hline $80 / 0 / 20$ & $10 \%$ & $>10 \%$ & $7.5 \%$ & $7.5 \%$ & $7.5 \%$ & $10 \%$ & $10 \%$ & $>10 \%$ & $>10 \%$ & $>10 \%$ & $>10 \%$ & $10 \%$ \\
\hline
\end{tabular}

E. coli was more vulnerable to powder $90 / 10 / 0$ for which MIC was $7.5 \%$, while for all other powders MIC was $10 \%$. For S. aureus the most effective powders with a MIC of $7.5 \%$ were $90 / 5 / 5,90 / 10 / 0,80 / 10 / 10,80 / 20 / 0$. L. monocytogenes, S. typhimurium, and B. cereus were equally susceptible to all powders which had a MIC of $7.5 \%$, while C. jejuni was most resistant to powders $90 / 0 / 10$ and $80 / 0 / 20$ (which contained $10 \%$ and $20 \%$ ratio of orange extract, respectively). C. perfringens was equally resistant to all powders which had a MIC of $10 \%$. With regard to the fungi, all tested cultures had a MIC above $10 \%$, except for $F$. oxysporum which was most susceptible to powders 100/0/0, 90/5/5, and 80/10/10 (with a MIC of $7.5 \%$ ), while all other powders had a MIC of $10 \%$ for F. oxysporum. Minimum lethal concentration (MLC) was higher than $10 \%$ for all bacterial and fungal cultures (data not shown), indicating that a higher concentration than $10 \%$ is needed for killing microbial 
cells with any of the tested powders, although a $7.5 \%$ or $10 \%$ could effectively control the growth of most bacteria and a few fungi (as shown by the MIC values).

\subsection{Inhibition of Growth Measured by Optical Density}

Since a $7.5 \%$ concentration was the minimum effective concentration of antimicrobial powders needed to inhibit the growth of many bacterial pathogens, this concentration was also applied in liquid cultures of bacteria and yeasts, where the optical density was measured, with or without the addition of antimicrobials, after appropriate incubation. The results shown in Figure 1 indicate that all tested powders conferred some antimicrobial activity in terms of reducing the optical density (O.D.) as well as the biomass of growing cells of all microorganisms. The largest reductions of O.D. were observed among bacterial cultures, compared to fungi (yeasts), which seemed more resistant, in agreement with the results of the MIC method. Powders $90 / 0 / 10$ and $80 / 0 / 20$ were more effective than the rest against $E$. coli and $S$. aureus, while $90 / 10 / 0$ was the most inhibitory towards $S$. typhimurium and especially $C$. jejuni. Samples $100 / 0 / 0$ and $90 / 5 / 5$ were very effective in controlling the growth of $L$. monocytogenes, while $10 / 0 / 0$ and $90 / 10 / 0$ were also effective against $B$. cereus and $C$. perfingens. The powder that contained only olive extract $(100 / 0 / 0)$ was also the most inhibitory in the case of S. cerevisiae and C. utilis, while R. mucilaginosa was better inhibited when the olive extract was combined with some pomegranate extract, as in the case of powders $90 / 10 / 0$ and $80 / 20 / 0$.

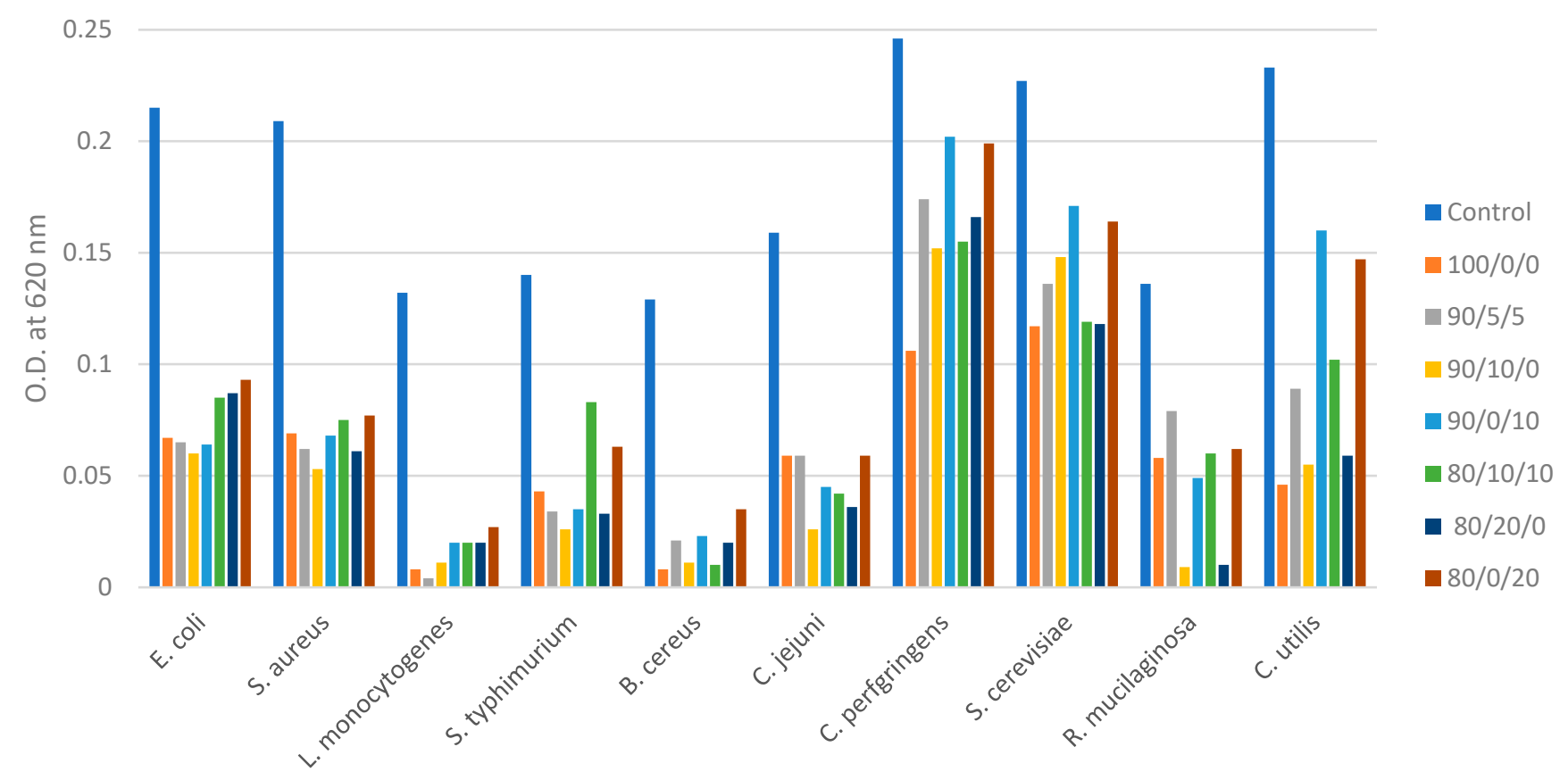

Figure 1. Measurement of optical density (O.D.) of liquid cultures of bacteria and yeasts in the presence of $7.5 \%$ of selected antimicrobial powders.

\subsection{Mycelium Growth Assay}

The mycelium growth assay of molds grown in the presence of $10 \%$ of antimicrobial powders revealed that the tested molds were less affected by the encapsulated antimicrobial extracts, in comparison to bacteria and yeasts. In fact, for some of the powders and the tested fungi, no practical restriction of mycelium expansion on agar plates was observed. As shown in Figure 2, P. expansum can be inhibited only slightly by powder 90/10/0, A. niger, can be inhibited mostly by powders $90 / 5 / 5$ and $90 / 10 / 0$. The powder $90 / 0 / 10$, A. flavus, is affected mostly by $90 / 10 / 0$ or $100 / 0 / 0$. P. italicum is inhibited mostly by 
$100 / 0 / 0$, while little antifungal effect is observed against $F$. oxysporum with any of the tested antimicrobials.

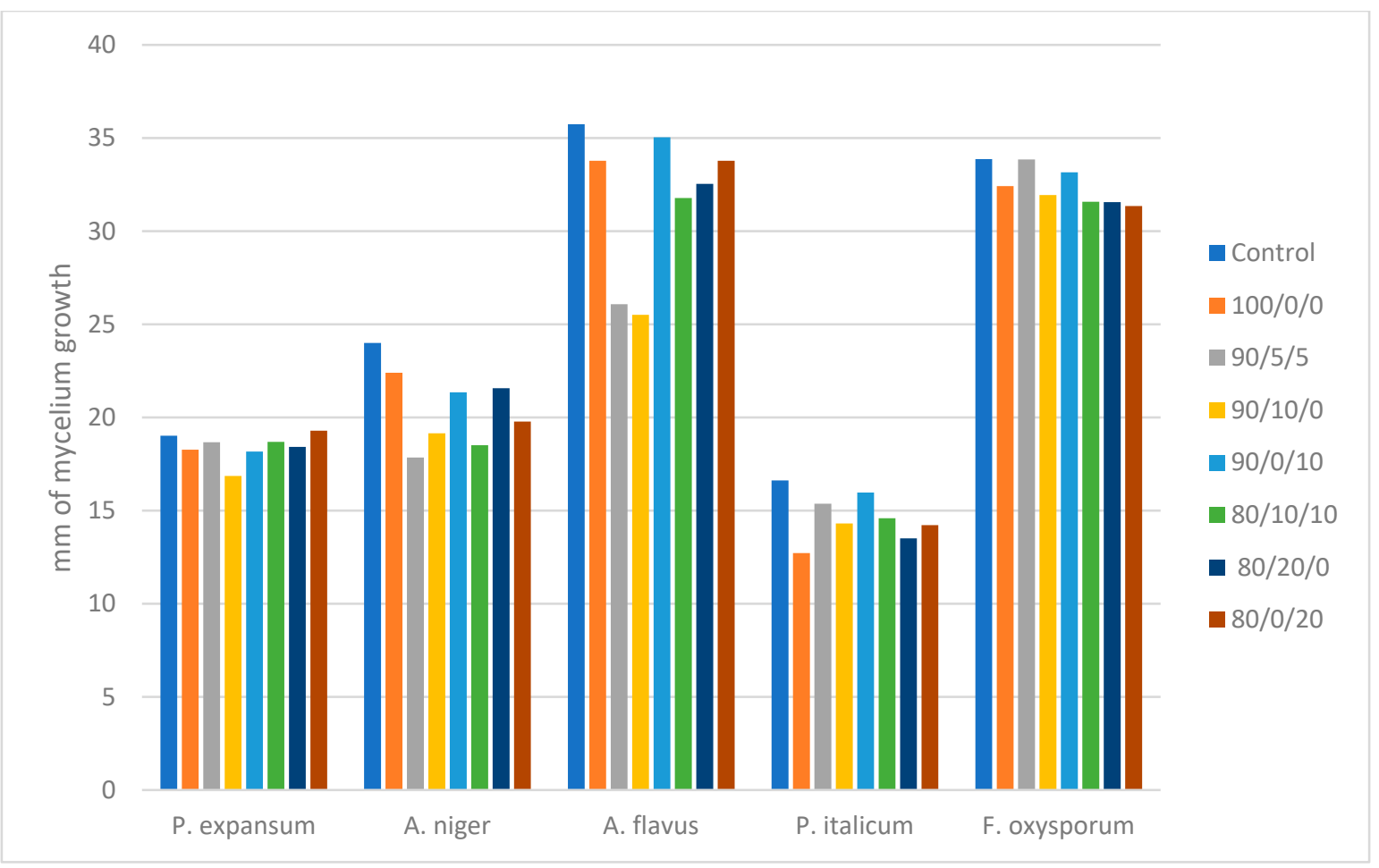

Figure 2. Mycelium growth of five different fungi with $10 \%$ of antimicrobial powders after 2, 4 , and 7 days of incubation.

\subsection{Antimicrobials Effects In Vivo (in Food Samples)}

Based on the results of in vitro antimicrobial activity, three antimicrobial powders were selected for further tests in different types of food in order to serve as natural preservatives and help extend the shelf-life and control the growth of food pathogens in vivo. Namely, powders $100 / 0 / 0$ and $90 / 10 / 0$, which seemed to be the two best performing antimicrobials in vitro, as well as powder $80 / 10 / 10$, which had a moderate antimicrobial effect in vitro and contained a ratio of $10 \%$ orange extract, were added in (a) fresh beef burger stored for 4 days at $4{ }^{\circ} \mathrm{C}$, (b) fresh soft cheese spread stored for 21 days at $4{ }^{\circ} \mathrm{C}$ (c) yogurt dessert stored for 21 days at $4{ }^{\circ} \mathrm{C}$, and (d) pasteurized tomato stored for 21 days at $4{ }^{\circ} \mathrm{C}$. E. coli, S. typhimurium, and L. monocytogenes were inoculated and used as hygiene/safety markers in fresh burger and fresh cheese spread, while A. niger, P. italicum, and R. mucilaginosa were inoculated in yogurt dessert and tomato juice, where they served as spoilage indicators. The results of microbial populations after appropriate storage showed that powder 100/0/0 was the most effective in reducing the growth of E. coli and L. monocytogenes in both burger and cheese spread by 0.6 to $1.8 \mathrm{log} \mathrm{cfu} / \mathrm{g}$, although $S$. typhimurium was better inhibited by $90 / 10 / 0$ in the burger and $100 / 0 / 0$ in the cheese spread (Figure 3 ). With regard to the food matrices inoculated with fungi, the powder $90 / 10 / 0$ was the most effective against all three fungal species, in both yogurt dessert and tomato juice, where it reduced fungal growth by $1-2.2 \log \mathrm{cfu} / \mathrm{g}$. This was a significant inhibition of microbial growth which could extend the shelf-life of these products, since fungi are the main source of spoilage in these products. Notably, the mixture of the three extracts in powder 80/10/10 worked better against fungi (compared to bacteria) in foods, and it seems that the presence of some orange extract $(10 \%)$ along with some pomegranate extract $(10 \%)$ could perform better as an antifungal in foods, in comparison to the previous in vitro tests. 


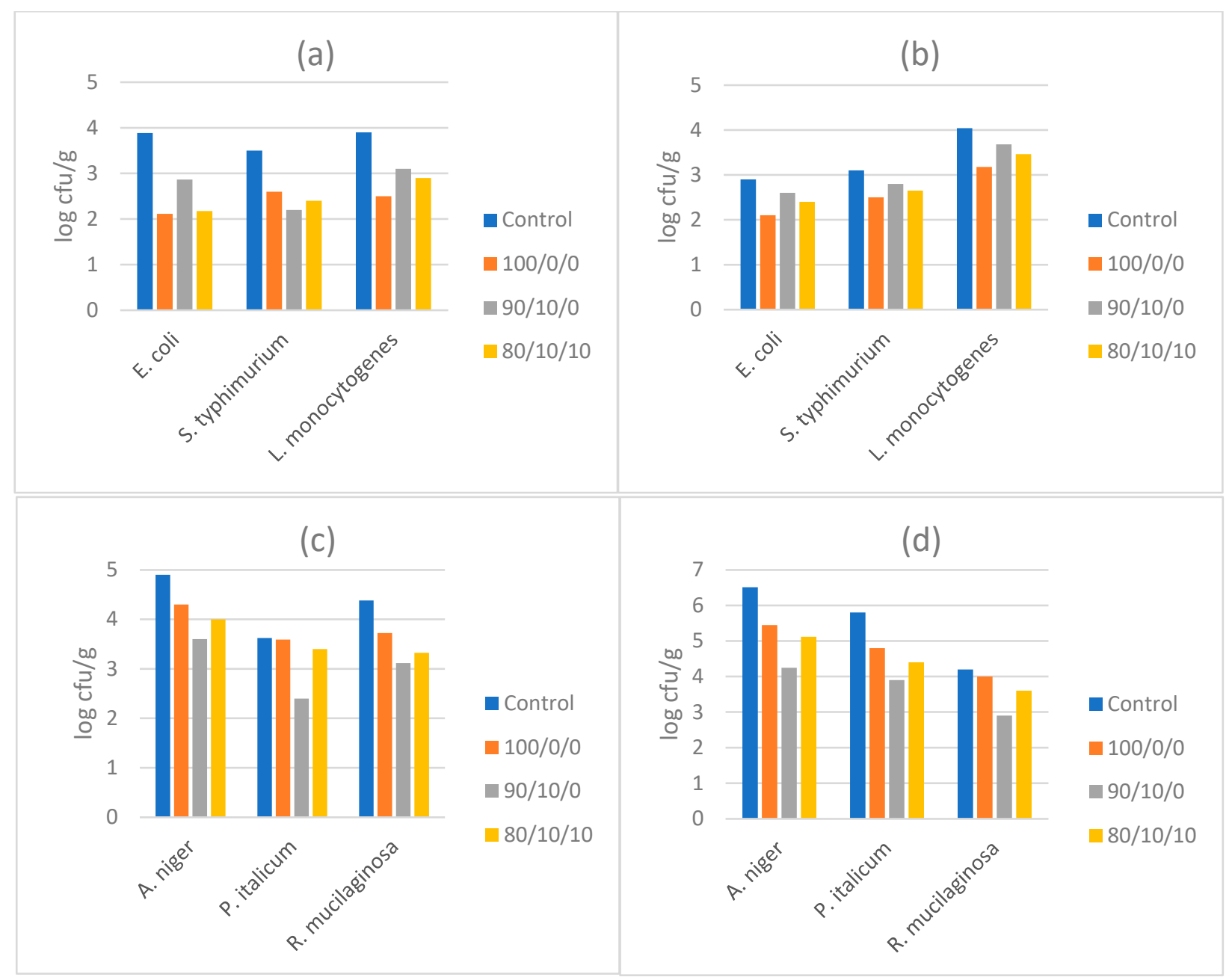

Figure 3. Populations ( $\log \mathrm{cfu} / \mathrm{g}$ ) of inoculated bacteria and fungi in four different food matrices, in the presence of selected antimicrobial powders, after appropriate storage. (a) Fresh burger after 4 days at $4{ }^{\circ} \mathrm{C},(\mathbf{b})$ fresh cheese spread after 21 days at $4{ }^{\circ} \mathrm{C}$ (c) yogurt after 21 days at $4{ }^{\circ} \mathrm{C}$, (d) tomato juice after 21 days at $4{ }^{\circ} \mathrm{C}$. (Mean values of triplicate measurements are presented).

The same selected antimicrobial powders of encapsulated extracts were also tested for the efficacy against spoilage indicators of the indigenous microbiota of fresh burgers and pasteurized tomato juice, stored at $4{ }^{\circ} \mathrm{C}$ in open containers. The results (Figure 4) showed that Total Plate Count (TPC) was not affected by the presence of any of the antimicrobial powders at $0.5 \%$ concentration, at least within the first 4 days of refrigerated storage. However, this may be due to the fact that the antimicrobial powders were not sterile and carried their own indigenous microbiota, which could contaminate the sample and contribute to the population of Total Plate Count (TPC), since the product was not pasteurized/sterilized or cooked. On the other hand, Enterobacteriaceae were clearly affected by the presence of all extracts and especially powder $100 / 0 / 0$ and $80 / 10 / 10$, which could lower the population by up to $1.5 \mathrm{log}$. In pasteurized tomato juice, yeasts and molds were reduced mostly by powder $90 / 10 / 0$ (by $1.5 \log$ on 21th day of storage), while lactic acid bacteria (LAB) were inhibited by all powders at $0.5 \%$ concentration, from which the powder $100 / 0 / 0$ seemed to be the most efficient, as it reduced microbial growth by $\sim 2-2.5 \log$ on the 14th and 21st day of storage. 


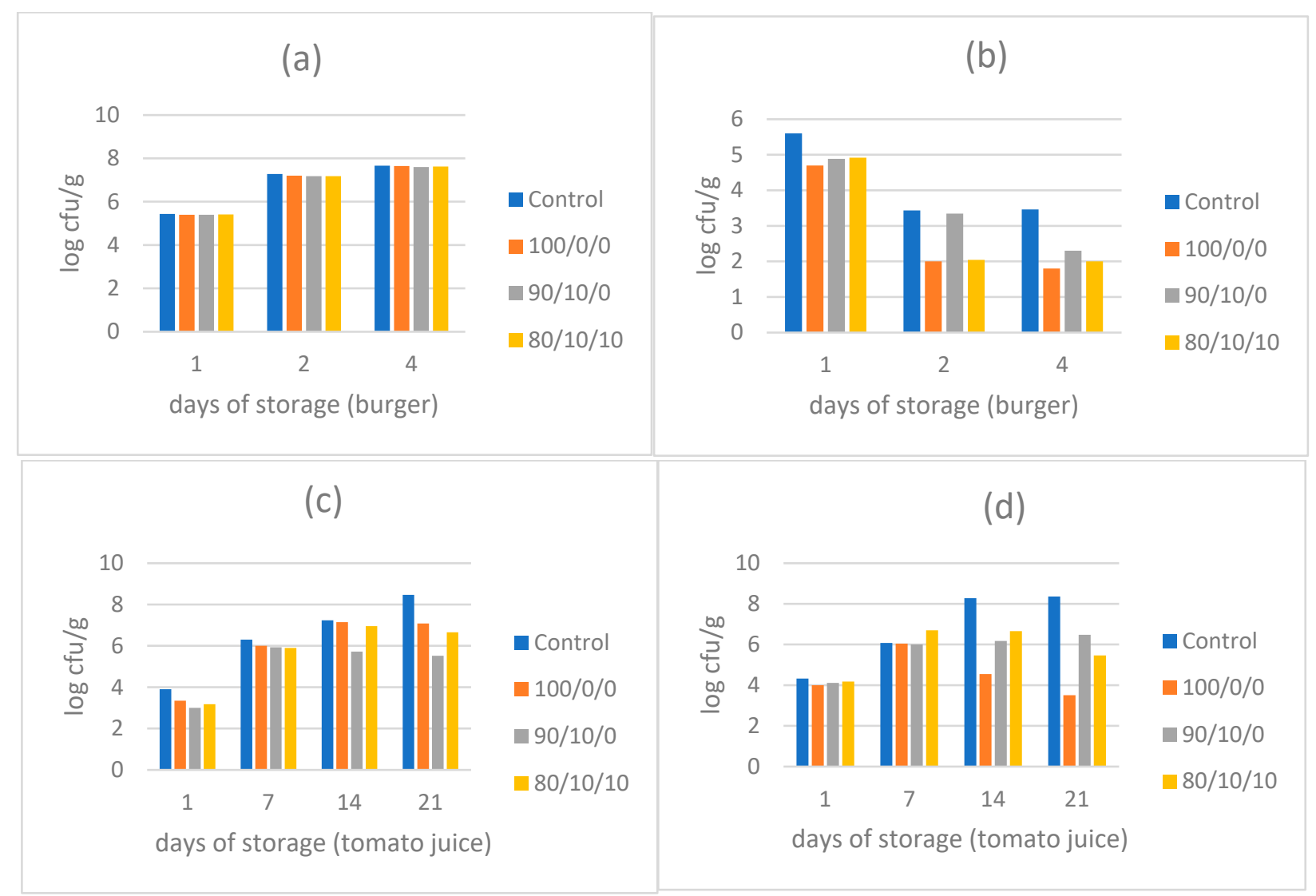

Figure 4. Populations ( $\log \mathrm{cfu} / \mathrm{g}$ ) of indigenous bacteria and fungi in two different food matrices, in the presence of selected antimicrobial powders, after appropriate storage at $4{ }^{\circ} \mathrm{C}$. (a) Total Plate Count in fresh burger, (b) Enterobacteriaceae in fresh burger, (c) yeasts and molds in tomato juice, (d) lactic acid bacteria in tomato juice.

\section{Discussion}

\subsection{In Vitro Antimicrobial Activity}

The antimicrobial efficiency of the different encapsulated antimicrobial powders was dependent on the tested microorganisms and the composition of each extract. The most sensitive bacteria according to MIC (Table 2) were S. typhimurium, L. monocytogenes, and B. cereus with a MIC of $7.5 \%$ for all tested extracts, while spore-forming C. perfringens was the most resistant bacterium with a MIC of $10 \%$ for all extracts. Comparatively, powder 90/10/0, which had the second highest content of both phenols and flavonoids (Table 1), also had the broadest antibacterial spectrum at a $7.5 \%$ concentration, as it could inhibit all tested bacteria, apart from C. perfingens, (which was inhibited only at 10\% concentration). The only powder that could not inhibit S. aureus at $10 \%$ was the $80 / 0 / 20$ (with the lowest content of phenols and 2nd lowest content of flavonoids).

The measurements of optical density (O.D.) of liquid cultures of bacteria and yeasts (Figure 2) showed that overall, the powders $100 / 0 / 0$ and $90 / 10 / 0$ had the highest antimicrobial activity against bacteria and yeasts, while the samples that were relatively rich in orange pulp extract $(80 / 0 / 20$ and $90 / 0 / 10)$ were the least effective, especially against fungi. Powder $80 / 20 / 0$ (the one with the highest content of pomegranate extract) was also an effective antimicrobial, especially against yeasts.

In similar studies of pomegranate peel and olive leaf extracts (water, ethanol, or methanol extracts) [24] a MIC of $2.5 \%$ to $30 \%$ were obtained against different bacterial pathogens, where each tested pathogen had a different degree of sensitivity to the tested extracts. This is partly in agreement with our results, although we had followed a different procedure for producing the pomegranate pulp and olive fruit extracts (without the use of organic solvents). In the work of Seddiek et al. [24] the pomegranate peel extract had a 
better antibacterial activity compared to the olive leaf extract, however, in our study where the whole pomegranate pulp (peel, flesh, and seeds) and olive fruit pulp extract were used, it appeared that a high olive fruit extract, with or without some addition of pomegranate extract are optimal for antimicrobial activity. Obviously, the type, and composition of raw materials, or even the genotype/variety of the plant source used for each extract [25], as well as the extraction method determine the level of the antimicrobial effect. A MIC of about $10 \%$ or lower seems to be average for antibacterial activity, as in the case of extracts of pomegranate arils, which had a MIC of 3-9\% against different pathogenic bacteria and yeast in vitro [25].

With regard to antifungal activity, the presence of orange extract at 10 or $20 \%$ (powders 90/0/10 and 80/0/20) seemed to lessen the inhibitory effects (Figure 1), most likely due to the lower content of phenols and flavonoids in that extract. This is in agreement with the previous reports on the limited antifungal effects of orange pulp extracts, in contrast to the presence of some antibacterial activity of orange pulp methanol extracts in vitro [26]. In general, fungi and especially molds were more resistant to all tested extracts, compared to bacteria, and the measurement of mycelium growth (Figure 2) revealed that little inhibition should be expected for some molds (such as P. expansum and F. oxysporum) with any of the tested extracts. Comparatively, the most inhibitory effect against molds in vitro was obtained with powder 90/10/0 and to a lesser extent powder 100/0/0 (Figure 2), indicating a potential synergy of pomegranate and olive extract against some fungi. However, if the pomegranate extract ratio was increased to $20 \%$ (in powder $80 / 20 / 0$ ) the inhibition of mycelium expansion could be impaired, which implies that olive extract is the most important antimicrobial agent in these powders and that if the olive extract ratio falls below $90 \%$, the synergism with pomegranate may be lost.

In a previous study by Leontopoulos et al. [5] where similar extracts of olive and pomegranate pulp were tested against phytopathogenic molds, it was found that the $100 \%$ olive pulp extract had the optimal antifungal activity against most plant pathogens, although a $100 \%$ pomegranate was also very effective against some other molds. In the same study, a very good antifungal activity in vitro was usually observed when the major component (70-100\% ratio) was an olive fruit extract and/or when pomegranate extract was added to at least $10 \%$ ratio. Orange pulp extract was the least effective antifungal agent in that study, in agreement with the results of the present study.

\subsection{Antimicrobial Activity In Vivo (in Food Samples)}

After the in vitro screening of antimicrobial capacity of the encapsulated extracts, their application in different food matrices was important in order to validate their efficiency in a more realistic and complex environment and estimate the practical benefits for food preservation and safety. In relation to the inoculated bacterial pathogens, the pure $(100 \%)$ olive pulp extract was the most preferable for controlling bacterial growth in fresh burger and cheese spread (Figure 3). No (significant) synergism was observed between olive and pomegranate extract (powder 90/10/0), or olive, pomegranate and orange extract $(80 / 10 / 10)$ and the reduction of the ratio of olive extract seemed to impair the antibacterial effect. This may be due to the fact that bacteria are more vulnerable to the high phenol content and most importantly the composition of phenols of olive fruit which are present in powder $10 / 0 / 0$.

In contrast, the inoculated fungi in yogurt and tomato juice were better inhibited with a combined extract of olive with some pomegranate, or even some orange pulp (Figure 3). The powder $90 / 10 / 0$ had the highest antifungal effect against the three fungi present in yogurt and tomato juice, while powder 80/10/10 also worked better than a pure olive fruit extract. This may mean that fungi are more susceptible to a higher content of flavonoids resulting from the presence of pomegranate, or a broader variety of phenols (such as punicalagin) with flavonoids (such as kaempferol, quercetin, myricetin, luteolin, and apigenin), tannins (such as ellagitannin) and anthocyanins (such as pelargonidin), 
which are present in pomegranate peel and/or pulp and associated with antimicrobial activity [27-29].

In non-inoculated food samples (Figure 4), the above results of inoculated samples were verified to a great extent. Enterobacteriaceae in fresh burgers and LAB in pasteurized tomato juice were better controlled with powder 100/0/0, meaning that a $100 \%$ olive fruit extract having the maximal content of phenols was the most effective. Similarly, lactic acid bacteria in tomato juice were mostly inhibited by the same powder, which seems to be optimal for antibacterial activity. Nevertheless, TPC did not seem to be affected by this or any other antimicrobial powder, at least in the first four days of storage of fresh burgers. This was most likely due to the fact that the powders were not sterile and the product was not cooked or thermally treated to kill any contaminating microbiota of encapsulated powders, thus the potential inhibitory effect of the encapsulated extracts was most likely counter-balanced and neutralized by the increase of TPC caused by the natural microbiota of each powder. In the case of yeast and molds in tomato juice, the powder $90 / 10 / 0$ containing $90 \%$ olive extract and $10 \%$ pomegranate extract was clearly the most effective antifungal agent in this food, showing a potential synergism of pomegranate extract with olive extract against fungi, which was also observed in inoculated samples (Figure 3). It seems that the high content of flavonoids in powder $90 / 10 / 0$, along with the combined phenol content of olive and pomegranate extract is preferable for controlling fungal spoilage in food samples.

The antimicrobial and potential preservative effect of pomegranate extracts was also recently investigated, in combination with avocado extracts in several food samples. It appeared that pomegranate pulp extracts had notable antifungal activity, but less pronounced antibacterial activity in perishable food products, most likely due to their high phenol and tannin-rich content [30]. Pomegranate extracts have been successfully used as antifungal agents for the preservation of fruits [31,32]. In addition, their antibacterial and antioxidant activity has been exploited in muscle foods such as meatballs, meat pate, chicken chili and chicken lollipops, several fish products, as well as dairy and fruit or vegetable products, where the water or alcohol extracts of pomegranate could inhibit the growth of pathogens such as L. monocytogenes, Bacillus subtilis, Bacillus cereus, Escherichia coli, Staphylococcus aureus, and fecal coliforms [33-37]. In processed poultry products the addition of pomegranate extracts could reduce TPC by 1.5-2.0 log and thus extend the shelf life [34], although the antimicrobial protection in foods related to storage temperature is reduced at temperatures above $4{ }^{\circ} \mathrm{C}$ [35].

As observed previously, the extracts of olive fruit that are disposed of as olive mill waste are rich in a variety of polyphenols and are efficient as antimicrobials against many phytopathogenic fungi and could be applied in the biological protection of fruits and vegetables from spoilage molds $[5,6,38,39]$. Besides, a significant antibacterial activity has also been reported for olive leaf extracts or olive fruit pulp extracts, which have been used in the preservation of minced meat, sausages, meat cubes, or seafood [40,41], due to their activity against food pathogens and spoilage bacteria.

The effectiveness of the olive fruit pulp or leaf extracts has already been exploited in commercial products for use in food, such as Medoliva ${ }^{\circledR}$, Medoliva Plus ${ }^{\circledR}$ [42] and HIDROX $^{\circledR}$ [43], which is especially rich in hydroxytorysol. However, one should keep in mind that in order to inhibit microbial growth, a combination of multiple polyphenols and antimicrobial polysaccharides (i.e., multiple hurdles) found in these olive extracts is more effective than the single use of pure and single active substances such as hydroxytyrosol, quercetin, or oleuropeine [44-46]. This highlights the complex interactions that exist in the mechanisms of antimicrobial activity in such plant extracts [40].

Apparently, as in all functional plant extracts, the composition and effectiveness of every extract varies according to the extraction conditions and the solvents used $[16,33,36]$, as in the case of methanol extracts of pomegranate peel, which are richer in phenolsand flavonoids than the water extracts [16]. However, using an organic solvent is a much more expensive and less sustainable solution, and in this context, one of the major advantages of 
the present study was that only water extracts were used, which are also readily compatible with all food and cosmetics applications.

Overall, based on the results of the present research, it can be deduced from the above that the water extracts of olive, pomegranate, and orange pulp can be utilized as effective antimicrobials in food or other applications, such as cosmetics, where they could serve not only as antimicrobials, but also as antioxidants. After a thorough screening of optimal powders via in vitro tests, the use of the relatively optimal antimicrobial powders in foods showed that the composition affects the antimicrobial activity: a single use of olive extracts seemed to be preferable for antibacterial activity in foods, while a combined use of olive extract (as the major ingredient) with some pomegranate extract (at 10\% ratio) results in maximal antifungal activity, possibly due to synergistic effects and the presence of a broader spectrum of antimicrobials from two different plant sources.

The goal of this work was to demonstrate the antimicrobial efficacy of these novel encapsulated natural ingredients, and it was found that olive fruit extracts, with or without the addition of some pomegranate extracts offer the optimal antimicrobial activity and are potential candidates for the replacement of synthetic preservatives in foods and cosmetics, or even antibiotics in animal breeding, which would be worth further investigation in the future.

\section{Materials and Methods}

\subsection{Preparation of Novel Olive, Pomegranate and Orange Extracts and Lyophilized Powders Thereof}

Three types of extracts were used. The olive fruit extract was produced commercially and obtained from the company Polyhealth S.A. (Larisa, Greece) in liquid form by the name Medoliva Liquid, which is an aqueous extract of Olea Europea (olive) fruit isolated after dialfiltration, microfiltration, and reverse osmosis of olive mill waste (OMW) via a patented process, and contains several olive phenols, mainly hydroxytyrosol, tyrosol, caffeic and coumaric acid, catechins, and anthocyanins [42]. The other two aqueous extracts were derived from the Punica granatum (pomegranate) juice pomace and from Citrus sinensis (L.) (orange) juice pomace, which are the solid by-products of the pomegranate and orange juice industry, respectively. Before obtaining the pomegranate and orange pomace aqueous extracts by "green" vacuum microwave extraction, the two extraction processes were optimized by a novel method, which has been described previously [22,23]. The two initial optimized extracts from pomegranate and orange pomace were treated with reverse osmosis at ambient conditions (temp $25^{\circ} \mathrm{C}$ ) under pressure of 26 bars, in order to achieve a 5 -fold concentration of each extract.

For the production of encapsulated powders of the above aqueous extracts, the three extracts were mixed in various ratios (Table 1) and in each mixture maltodextrin DE18 dry powder $(120 \mathrm{~g})$ and distilled water was added, up to a final mass of $600 \mathrm{~g}$. Then this mixture was homogenized by an Ultrasound homogenizer (model UIP1000hdT, $1000 \mathrm{~W}$, $20 \mathrm{kHz}$, Hielscher, Teltow, Germany) (Figure 5) and the finished liquid, which had a dry solid content of about $30 \% w / w$, was finally freeze dried using an industrial freeze dryer with a total capacity $100 \mathrm{Kg}$ (model EKS 100-10, Zirbus Technology GmbH, Bad Grund, Harz, Germany) (Figure 4). The total lyophilization cycle lasted $21 \mathrm{~h}$, including $2 \mathrm{~h}$ of freezing at $-35^{\circ} \mathrm{C}$.

Different antimicrobial powders were prepared, based on encapsulated olive, pomegranate, and orange extracts, in order to determine their potential synergistic action in relation to their antimicrobial activity. The initial number of the lyophilized powders with different concentrations of olive, pomegranate, and orange extracts were 72 , as described previously [5]. These were limited to the seven best powders shown in Table 1, based on preliminary in vitro tests (data not shown) and previous research [5] which showed that for optimal antimicrobial activity olive extract was the most crucial ingredient and antimicrobial effects were reduced if the olive extract was used at a ratio below $70 \%$. Therefore, the encapsulated antimicrobial powders studied here were produced from a liquid extract composed of at least $80 \%$ olive fruit extract and $0-20 \%$ of pomegranate and/or orange 
extract, in order to study any potential synergistic effects of the three extracts (when olive extract was the major component). The coding of samples of encapsulated extracts is also explained in Table 3.
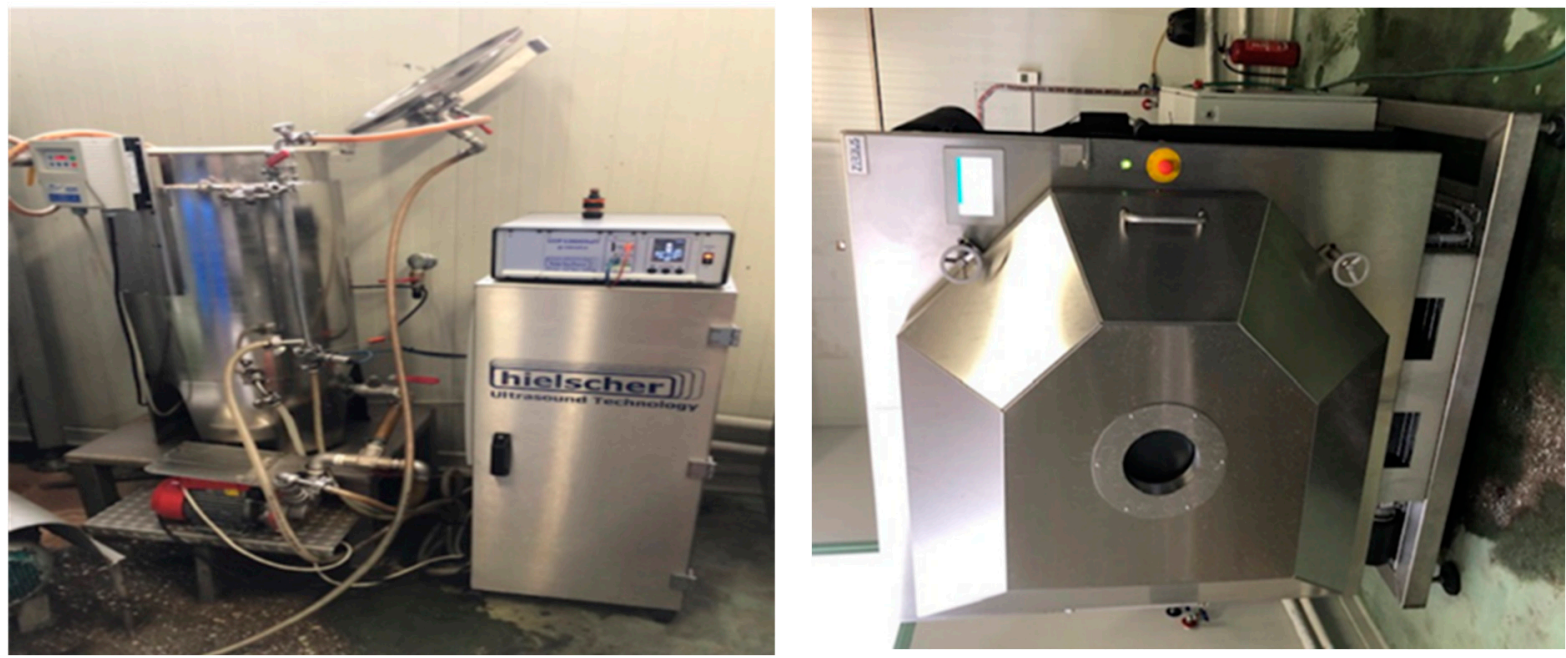

Figure 5. Industrial ultrasound homogenizer, Hielscher model UIP1000hdT (left) and industrial freeze dryer Zirbus GmbH model EKS 100-109 (right).

Table 3. Coding of samples of selected antimicrobial powders and relative ratio (\%) of the three different extracts of olive, pomegranate, and orange.

\begin{tabular}{cccc}
\hline Powder Code No. & Olive Extract Ratio & Pomegranate Extract Ratio & Orange Extract Ratio \\
\hline $100 / 0 / 0$ & 100 & 0 & 0 \\
\hline $90 / 5 / 5$ & 90 & 5 & 5 \\
\hline $90 / 10 / 0$ & 90 & 10 & 0 \\
\hline $90 / 0 / 10$ & 90 & 0 & 10 \\
\hline $80 / 10 / 10$ & 80 & 10 & 10 \\
\hline $80 / 20 / 0$ & 80 & 20 & 0 \\
\hline $80 / 0 / 20$ & 80 & 0 & 20 \\
\hline
\end{tabular}

\subsection{Measurement of Total Phenols and Flavonoids of the Lyophilized Powders}

For the measurement of the total phenolic content (expressed as gallic acid) a modified Folin-Ciocalteu method was used [47]. According to this method, each encapsulated antimicrobial powder (sample) was appropriately diluted (e.g., 1/10 dilution ratio) in deionized water and $0.2 \mathrm{~mL}$ of this solution was mixed with $10.8 \mathrm{~mL}$ of distilled water, $8 \mathrm{~mL}$ of $\mathrm{Na}_{2} \mathrm{CO}_{3}$ solution (prepared by dissolving $75 \mathrm{~g} \mathrm{Na}_{2} \mathrm{CO}_{3}$ in $1 \mathrm{~L}$ distilled water), and $1 \mathrm{~mL}$ Folin-Ciocalteu reagent. All samples were homogenized in the vortex and then placed in a dark cabinet for $1 \mathrm{~h}$ at room temperature. After this incubation, the absorbance was measured at $750 \mathrm{~nm}$ using a UV-Vis spectrophotometer (DR 5000, Hach Lange, Loveland, CO, USA). Deionized water was used as a blank sample. The standard curve was prepared with standard solutions of gallic acid, with concentrations ranging from 0 to $1000 \mu \mathrm{g} / \mathrm{mL}$.

Total flavonoids were measured by the aluminum chloride method described by Hassan et al. [48], with a few modifications. Briefly, $1 \mathrm{~g}$ of antimicrobial powder was dissolved in $80 \%$ ethanol up to a total volume of $25 \mathrm{~mL}$. After mixing in the vortex, it was left overnight at room temperature and then centrifuged at $5000 \mathrm{rpm}$ for $10 \mathrm{~min}$. The supernatant was filter with plain filter paper and $0.5 \mathrm{~mL}$ of this sample was mixed with $1.5 \mathrm{~mL}$ of $95 \%$ Ethanol, $0.1 \mathrm{~mL}$ of $10 \% \mathrm{AlCl}_{3}, 0.1 \mathrm{~mL}$ of $1 \mathrm{M}$ Potassium Acetate, $2.8 \mathrm{~mL}$ distilled $\mathrm{H}_{2} \mathrm{O}$ and incubated at room temperature for $30 \mathrm{~min}$, after which the absorbance 
was measured at $415 \mathrm{~nm}$. A blank sample was prepared by replacing $\mathrm{AlCl}_{3}$ with $0.1 \mathrm{~mL}$ $\mathrm{H}_{2} \mathrm{O}$ distilled. The standard curve was prepared with quercetin standard solutions (in $89 \%$ ethanol), ranging from 0 to $100 \mu \mathrm{g} / \mathrm{mL}$ concentration.

\subsection{Cultures of Microorganism}

The in vitro antimicrobial assessment of these novel powders was evaluated against several foodborne pathogens and spoilage microorganisms, which are particularly important for food safety and quality. The bacterial and yeasts cultures used in this study were obtained by DSMZ Culture Collection (Braunschweig, Germany), while the molds were kindly provided by the Benakion Phytopathological Institute of Greece.The bacterial cultures were maintained in Tryptone Soy Broth (TSB) (Neogen, Lansing, MI, USA), while fungal cultures were maintained in Potato Dextrose Broth (PDB) (Neogen, Lansing, MI, USA). For the determination of the population in food matrices, each target microorganism was cultured in (selective) agar medium. Escherichia coli was cultivated in TBX agar (Oxoid, Basingstoke, UK) at $37^{\circ} \mathrm{C}$ for $24 \mathrm{~h}$, Enterobacteriaceae were counted in Violet Red Bile Glucose agar (Neogen, USA) at $37^{\circ} \mathrm{C}$ for $24 \mathrm{~h}$, Listeria monocytogenes was counted on Harlequin Listeria Chromogenic Agar (Ottaviani and Agosti) (Neogen, Lansing, MI, USA), supplemented with Brilliance Listeria Differential supplement and OCLA (ISO) Selective supplement, Salmonella typhimurium was cultivated on XLD agar (Oxoid, Basingstoke, UK) at $37^{\circ} \mathrm{C}$ for $24 \mathrm{~h}$. Lactic acid bacteria were cultivated in MRS agar (Oxoid, Basingstoke, UK) at $37^{\circ} \mathrm{C}$ for $48 \mathrm{~h}$ and Clostridium perfringens was counted in TSC agar (Oxoid, Basingstoke, $\mathrm{UK})$ at $37^{\circ} \mathrm{C}$ for $48 \mathrm{~h}$ under anaerobic conditions. With regard to the enumeration of fungi, all yeast and molds were cultivated in Potato Dextrose agar (Oxoid, Basingstoke, UK) at $25^{\circ} \mathrm{C}$ for $3-5$ days.

\subsection{Minimum Inhibitory Concentration (MIC) and Minimum Lethal Concentration (MLC)}

In this method, the tested antimicrobial powders were added in test tubes at a concentration of $0 \%$ (control without antimicrobial powder), $2.5 \%, 5 \%, 7.5 \%$, and $10 \%$ in $10 \mathrm{~mL}$ of either TSB (for bacteria) or PDB (for fungi). After sterilization and inoculation with $0.1 \mathrm{~mL}$ of a fresh bacterial or fungal culture, the bacterial cultures were incubated for up to $48 \mathrm{~h}$ and fungal cultures were incubated for up to $96 \mathrm{~h}$. After the incubation, the presence or absence of growth (evidenced by sediment or turbidity for bacteria and yeasts, and the appearance of superficial mycelium on top of the liquid culture for molds) was recorded. The minimum concentration of antimicrobial powder where no growth was observed was recorded as MIC. For the determination of MLC, all tubes at or above the MIC level were sub-cultured in fresh TSB/PDB without the addition of antimicrobials, and after appropriate incubation the test tubes were again checked for evidence or absence of growth. Absence of growth at that second stage meant that cells were dead at the corresponding concentration of the first step of MIC. MLC is the lowest concentration of antimicrobials at which all target cells are dead.

\subsection{Measurement of Optical Density of Microbial Cultures}

The measurement of the optical density (O.D.) is an indication of the number of cells in a liquid culture. In this assay, liquid cultures in TSB or PDB broth were incubated in the presence of $7.5 \%$ of each antimicrobial powder, in order to determine the relative ability of each antimicrobial powder to limit microbial growth and thus limit the value of O.D. After sterilization of liquid media (TSB or PDB) and inoculation with $0.1 \mathrm{~mL}$ of fresh culture of each target microorganism (bacteria or yeasts), each culture was incubated for $24 \mathrm{~h}$ at $37^{\circ} \mathrm{C}$ (bacteria) or $25^{\circ} \mathrm{C}$ (yeasts). In addition, cultures without any antimicrobial powder were incubated under the same conditions and were used as a control. At the end of the incubation, each culture was diluted at a 1/10 ratio with deionized water and its O.D. was measured in a UV-Vis spectrophotometer (DR 5000, Hach Lange) at $620 \mathrm{~nm}$. The average values of duplicate measurements are reported here. 
The target microorganisms used in this assay were: Escherichia coli, Staphylococus aureus, Listeria monocytogenes, Salmonella typhimurium, Bacillus cereus, Campylobacter jejuni, Clostridium perfringens, Saccharomyces cerevisiae, Rhodotorula mucilaginosa, and Candida utilis.

\subsection{Mycelium Growth Assay}

For this method 51 encapsulated powders (Table 1) evaluated against six spoilage fungi, Penicillium expansum, Penicillium italicum BPIC 1904, Aspergillus flavus, Aspergillus niger, Fusarium oxysporum, and Geotrichum candidum for their antifungal activity. From each powder a $10 \%$ solution ( $1 \mathrm{~g}$ powder in $10 \mathrm{~mL}$ of distilled water) was prepared and then sterilized in an autoclave at $121{ }^{\circ} \mathrm{C}$ for $15 \mathrm{~min}$. Then, $20 \mathrm{~mL}$ of Potato Dextrose Agar (Oxoid, UK) was poured in petri dishes. Once the petri dishes were cooled down, $0.1 \mathrm{~mL}$ of each solution was spread on the plate and left for $1 \mathrm{~h}$ so that the solution could be absorbed by the agar. With a sterile glass Paster pipette, a small well was opened in which $25 \mu \mathrm{L}$ of spore suspension of each fungi was added. An agar plate with each fungi was also prepared without the addition of any antimicrobial substance, which served as a control. All agar plates were incubated at room temperature $\left(25^{\circ} \mathrm{C}\right)$ for 7 days, and the $\mathrm{mm}$ of mycelium growth was measured at the end of the incubation period. An average of four measurements was reported as the mean diameter of mycelium expansion for each mold.

\subsection{In Vivo Antimicrobial Activity (Application in Food Samples)}

For the examination of the antimicrobial activity of selected antimicrobial extracts in a realistic food environment, with a concentration of $0.5 \%$ the encapsulated powders 100/0/0,90/10/0, and 80/10/10 were applied and compared to a control treatment without antimicrobials in the following food samples:

(a) A fresh pork/beef burger stored for 4 days at $4{ }^{\circ} \mathrm{C}$;

(b) A fresh cheese spread stored for 21 days at $4{ }^{\circ} \mathrm{C}$;

(c) A fresh yogurt stored for 21 days at $4{ }^{\circ} \mathrm{C}$;

(d) A fresh pasteurized tomato juice stored 21 days at $4{ }^{\circ} \mathrm{C}$.

All food samples were produced in the lab. The burger was prepared from $50 \%$ fresh pork and $50 \%$ fresh beef minced meat without any other additives or spices. The fresh cheese spread was produced my mixing and homogenizing in a home blender with a mixture of $70 \%$ myzithra cheese (a traditional Greek cheese produced from clotted cheese whey) and 30\% feta cheese. The fresh yogurt was produced from full fat fresh cow's milk after a $4 \mathrm{~h}$ incubation with yogurt culture at $44^{\circ} \mathrm{C}$, while the tomato juice was produced from sliced and blended fresh tomatoes, which were by condensed by boiling to $3 / 4$ of the initial volume ( $25 \%$ condensed) and then pasteurized in glass bottles at $80^{\circ} \mathrm{C}$ for $30 \mathrm{~min}$ in order to kill any autochthonous fungi present in the raw materials.

The above food samples were either inoculated with pure cultures of pathogens or fungi, or tested for their natural, indigenous microbiota and analyzed in triplicate (the mean values are reported here). In the case of inoculated samples, the microbial cultures were prepared as described in 4.3 and diluted to $1 / 10$ with Maximum Recovery Diluent (Neogen, USA) before being added into the above food samples. All four types of food samples were prepared in triplicate and inoculated with $1 \%$ inoculum $(1 \mathrm{~mL}$ of microbial culture into $100 \mathrm{~g}$ of food sample) of food pathogens and spoilage microbiota, as follows: the fresh burgers and fresh cheese spread were inoculated with Escherichia coli, Salmonella typhimurium and Listeria monocytogenes, since these types of food are vulnerable to growth of bacterial pathogens, while the fresh yogurt and tomato juice were inoculated with spoilage fungi, which may occur in such products, namely Aspergillus niger, Penicillium italicum, and Rhodotorula mucilaginosa. The inoculated food samples were homogenized in a stomacher for $1 \mathrm{~min}$ in order to distribute the inoculum and they were then stored in sterile containers at $4{ }^{\circ} \mathrm{C}$ for 21 days, except for the burgers, which were stored for 4 days. The duration of storage of each sample corresponded to an average ordinary duration of 
refrigerated storage of fresh burgers, fresh cheese spread, yogurt, and non-sterile or fresh tomato juice.

For the determination of indigenous spoilage indicators, the beef burgers and the pasteurized tomato juice were placed in clean, non-sterile containers in the refrigerator (at $4{ }^{\circ} \mathrm{C}$ ), after being exposed to natural air contamination and stored for 4 (fresh burger) or 21 (tomato juice) days. The burgers were analyzed for the determination of Total Plate Count (TPC), i.e., the total aerobic mesophilic bacteria, while the total population of yeasts and molds and lactic acid bacteria (LAB) were determined in the tomato juice during storage. These microorganisms were chosen as typical sources of microbial spoilage during storage of fresh minced burgers and opened containers of tomato juice, respectively.

\section{Conclusions}

Using a sustainable, green process for the utilization of olive mill waste, pomegranate, and orange pulp, different combinations of antimicrobial encapsulated extracts were produced and studied in vitro and in food matrices. A concentration of 7.5-10\% of the antimicrobial powders could inhibit bacterial growth in vitro, while fungal growth was inhibited at or above $10 \%$ content in synthetic growth media. In food samples, the optimal antimicrobial powder containing $100 \%$ olive fruit extract led to a reduction of the bacterial population by up to $1.8 \mathrm{log} \mathrm{cfu} / \mathrm{g}$, while fungal growth in foods was decreased by up to $2.2 \log \mathrm{cfu} / \mathrm{g}$ after addition of an encapsulated extract containing $90 \%$ olive fruit extract and $10 \%$ pomegranate pulp extract. This level of antimicrobial activity is significant, especially in the context of food safety and microbiological quality.

Although processing and extraction conditions may alter the composition and antimicrobial activity of such extracts, the present results show that there is room for potential commercial exploitation of these single or combined fruit extracts in food preservation and in the microbial safety of animals and humans, in an environmentally friendly manner, under the framework of a sustainable and circular economy.

Author Contributions: Experimental design, K.P. and I.G.; experiment supervision, I.G.; analysis, C.M.; writing, I.G. and C.M. All authors have read and agreed to the published version of the manuscript.

Funding: This research was co-funded by the European Regional Development Fund of the European Union and Greek national funds through the Operational Program Competitiveness, Entrepreneurship, and Innovation, under the call Research-Create-Innovate (Project code: T1EDK-03942).

Institutional Review Board Statement: Not applicable.

Informed Consent Statement: Not applicable.

Data Availability Statement: The data presented in this study are available on request from the corresponding author.

Conflicts of Interest: The authors declare no conflict of interest.

Sample Availability: Samples of the compounds are available from the authors.

\section{References}

1. Corrado, S.; Sala, S. Food waste accounting along global and European food supply chains: State of the art and outlook. Waste Manag. 2018, 79, 120-131. [CrossRef]

2. Beltrán-Ramírez, F.; Orona-Tamayo, D.; Cornejo-Corona, I.; González-Cervantes, J.L.N.; de Jesús Esparza-Claudio, J.; QuintanaRodríguez, E. Agro-industrial waste revalorization: The growing biorefinery. In Biomass for Bioenergy-Recent Trends and Future Challenges; Abomohra, A.E.-F., Ed.; IntechOpen: London, UK, 2019; pp. 83-102.

3. Caporaso, N.; Formisano, D.; Genovese, A. Use of phenolic compounds from olive mill wastewater as valuable ingredients for functional foods. Crit. Rev. Food Sci. Nutr. 2018, 58, 2829-2841. [CrossRef]

4. Kafantaris, I.; Stagos, D.; Kotsampasi, B.; Hatzis, A.; Kypriotakis, A.; Gerasopoulos, K.; Makri, S.; Goutzourelas, N.; Mitsagga, C.; Giavasis, I.; et al. Grape pomace improves performance, antioxidant status, fecal microbiota and meat quality of piglets. Animal 2018, 12, 246-255. [CrossRef] [PubMed] 
5. Leontopoulos, S.; Mitsagga, C.; Giavasis, I.; Papaioannou, C.; Vasilakoglou, I.; Petrotos, K. Potential Synergistic Action of Liquid Olive Fruit Polyphenol Extract with Aqueous Extracts of Solid Wastes of Pomegranate or/and Orange Juice Industry as Organic Phyto-protective Agents against Important Plant Pathogens-Part 1 (in vitro Studies). Univers. J. Agric. Res. 2020, 8, $202-222$. [CrossRef]

6. Leontopoulos, S.V.; Petrotos, K.B.; Kokkora, M.I.; Giavasis, I.; Papaioannou, C. In vivo evaluation of liquid polyphenols obtained from OMWW as natural bio-chemicals against several fungal pathogens on tomato plants. Desal Water Treatm. 2016, 57, 20646-20660.

7. Elsherbiny, E.A.; Amin, B.H.; Baka, Z.A. Efficiency of pomegranate (Punica granatum L.) peels extract as a high potential natural tool towards Fusarium dry rot on potato tubers. Postharvest Biol. Tec. 2016, 111, 256-263. [CrossRef]

8. Osorio, L.L.D.R.; Flórez-López, E.; Grande-Tovar, C.D. The Potential of Selected Agri-Food Loss and Waste to Contribute to a Circular Economy: Applications in the Food, Cosmetic and Pharmaceutical Industries. Molecules 2021, 26, 515. [CrossRef]

9. Chowdhury, A.K.M.M.B.; Akratos, C.S.; Vayenas, D.V.; Pavlou, S. Olive mill waste composting: A review. Int. Biodeterior. Biodegrad. 2013, 85, 108-119. [CrossRef]

10. Belaqziz, M.; El-Abbassi, A.; Agrafioti, E.; Galanakis, C.M. Agronomic application of olive mill wastewater: Effects on maize production and soil properties. J. Environ. Manag. 2016, 171, 158-165. [CrossRef]

11. Paulo, F.; Santos, L. Deriving valorization of phenolic compounds from olive oil by-products for food applications through microencapsulation approaches: A comprehensive review. Crit. Rev. Food Sci. Nutr. 2021, 61, 920-945. [CrossRef]

12. Leouifoudi, I.; Harnafi, H.; Zyad, A. Olive mill waste extracts: Polyphenols content, antioxidant, and antimicrobial activities. Adv. Pharmacol. Sci. 2015, 2015, 714138. [CrossRef] [PubMed]

13. Casquete, R.; Castro, S.M.; Martín, A.; Ruiz-Moyano, S.; Saraiva, J.A.; Córdoba, M.G.; Teixeira, P. Evaluation of the effect of high pressure on total phenolic content, antioxidant and antimicrobial activity of citrus peels. Innov. Food Sci. Emerg. Technol. 2015, 31, 37-44. [CrossRef]

14. Geraci, A.; Di Stefano, V.; Di Martino, E.; Schillaci, D.; Schicchi, R. Essential oil components of orange peels and antimicrobial activity. Nat. Prod. Res. 2017, 31, 653-659. [CrossRef] [PubMed]

15. Dhanavade, M.J.; Jalkute, C.B.; Ghosh, J.S.; Sonawane, K.D. Study antimicrobial activity of lemon (Citrus lemon L.) peel extract. Br. J. Pharmac. Toxic. 2011, 2, 119-122.

16. Al-Zoreky, N.S. Antimicrobial activity of pomegranate (Punica granatum L.) fruit peels. Int. J. Food Microbiol. 2009, 134, 244-248. [CrossRef]

17. Li, Y.; Guo, C.; Yang, J.; Wei, J.; Xu, J.; Cheng, S. Evaluation of antioxidant properties of pomegranate peel extract in comparison with pomegranate pulp extract. Food Chem. 2006, 96, 254-260. [CrossRef]

18. Skenderidis, P.; Leontopoulos, S.; Petrotos, K.; Giavasis, I. Optimization of Vacuum Microwave-Assisted Extraction of Pomegranate Fruits Peels by the Evaluation of Extracts' Phenolic Content and Antioxidant Activity. Foods 2020, 9, 1655. [CrossRef]

19. Skenderidis, P.; Mitsagga, C.; Giavasis, I.; Petrotos, K.; Lampakis, D.; Leontopoulos, S.; Hadjichristodoulou, C.; Tsakalof, A. The in vitro antimicrobial activity assessment of ultrasound assisted Lycium barbarum fruit extracts and pomegranate fruit peels. J. Food Meas. Character 2019, 13, 2017-2031. [CrossRef]

20. Tsagaraki, E.; Lazarides, H.N.; Petrotos, K.B. Olive mill wastewater treatment. In Utilization of By-Products and Treatment of Waste in the Food Industry; Springer: Boston, MA, USA, 2007; pp. 133-157.

21. Giavasis, I.; Tsante, E.; Goutsidis, P.; Papatheodorou, K.; Petrotos, K. Stimulatory effect of novel polyphenol-based supplements from olive mill waste on the growth and acid production of lactic acid bacteria. In Microbes in Applied Research: Current Advances and Challenges; Mendez-Vilas, A., Ed.; World Scientific Publishing Group: London, UK, 2012; pp. 308-312.

22. Petrotos, K.; Giavasis, I.; Gerasopoulos, K.; Mitsagga, C.; Papaioannou, C.; Gkoutsidis, P. Optimization of the Vacuum Microwave Assisted Extraction of the Natural Polyphenols and Flavonoids from the Raw Solid Waste of the Pomegranate Juice Producing Industry at Industrial Scale. Molecules 2021, 26, 1033. [CrossRef]

23. Petrotos, K.; Giavasis, I.; Gerasopoulos, K.; Mitsagga, C.; Papaioannou, C.; Gkoutsidis, P. Optimization of Vacuum-MicrowaveAssisted Extraction of Natural Polyphenols and Flavonoids from Raw Solid Waste of the Orange Juice Producing Industry at Industrial Scale. Molecules 2021, 26, 246. [CrossRef]

24. Seddiek, A.S.; Hamad, G.M.; Zeitoun, A.A.; Zeitoun, M.A.; Ali, S. Antimicrobial and antioxidant activity of some plant extracts against different food spoilage and pathogenic microbes. Eur. J. Nutr. Food Saf. 2020, 12, 1-12. [CrossRef]

25. Duman, A.D.; Ozgen, M.; Dayisoylu, K.S.; Erbil, N.; Durgac, C. Antimicrobial activity of six pomegranate (Punica granatum L.) varieties and their relation to some of their pomological and phytonutrient characteristics. Molecules 2009, 14, $1808-1817$. [CrossRef] [PubMed]

26. Mostafa, R.M.; Essawy, H.S. Screening and Quantification of Bioactive Compounds and Antimicrobial Activities of Fresh Juice, Methanolic Peel and Pulp Extract of Citrus sinensis L. (Sweet Orange). Egypt. Acad. J. Biol. Sci. G. Microbiol. 2021, 13, 1-10. [CrossRef]

27. Chen, J.; Liao, C.; Ouyang, X.; Kahramanoğlu, I.; Gan, Y.; Li, M. Antimicrobial activity of pomegranate peel and its applications on food preservation. J. Food Qual. 2020, 2020, 8850339. [CrossRef]

28. Yuan, Z.; Fang, Y. Flavonols and Flavones Changes in Pomegranate (Punica granatum L.) Fruit Peel during Fruit Development. J. Agric. Sci. Technol. 2014, 16, 1649-1659. 
29. Abid, M.; Yaich, H.; Cheikhrouhou, S.; Khemakhem, I.; Bouaziz, M.; Attia, H.; Ayadi, M.A. Antioxidant properties and phenolic profile characterization by LC-MS/MS of selected Tunisian pomegranate peels. J. Food Sci. Technol. 2017, 54, 2890-2901. [CrossRef]

30. Skenderidis, P.; Leontopoulos, S.; Petrotos, K.; Mitsagga, C.; Giavasis, I. The In Vitro and In Vivo Synergistic Antimicrobial Activity Assessment of Vacuum Microwave Assisted Aqueous Extracts from Pomegranate and Avocado Fruit Peels and Avocado Seeds Based on a Mixtures Design Model. Plants 2021, 10, 1757. [CrossRef]

31. Nicosia, M.G.L.D.; Pangallo, S.; Raphael, G.; Romeo, F.V.; Strano, M.C.; Rapisarda, P.; Schena, L. Control of postharvest fungal rots on citrus fruit and sweet cherries using a pomegranate peel extract. Postharv. Biol. Technol. 2016, 114, 54-61. [CrossRef]

32. Molva, Ç.; Baysal, A.H. Evaluation of bioactivity of pomegranate fruit extract against Alicyclobacillus acidoterrestris DSM 3922 vegetative cells and spores in apple juice. LWT 2015, 62, 989-995. [CrossRef]

33. Smaoui, S.; Hlima, H.B.; Mtibaa, A.C.; Fourati, M.; Sellem, I.; Elhadef, K.; Ennouri, K.; Mellouli, L. Pomegranate peel as phenolic compounds source: Advanced analytical strategies and practical use in meat products. Meat Sci. 2019, 158, 107914. [CrossRef]

34. Kanatt, S.R.; Chander, R.; Sharma, A. Antioxidant and antimicrobial activity of pomegranate peel extract improves the shelf life of chicken products. Int. J. Food Sci. Technol. 2010, 45, 216-222. [CrossRef]

35. Hayrapetyan, H.; Hazeleger, W.C.; Beumer, R.R. Inhibition of Listeria monocytogenes by pomegranate (Punica granatum) peel extract in meat paté at different temperatures. Food Contr. 2012, 23, 66-72. [CrossRef]

36. M'hiri, N.; Ioannou, I.; Boudhrioua, N.M.; Ghoul, M. Effect of different operating conditions on the extraction of phenolic compounds in orange peel. Food Bioprod Process. 2015, 96, 161-170. [CrossRef]

37. Kaderides, K.; Kyriakoudi, A.; Mourtzinos, I.; Goula, A.M. Potential of pomegranate peel extract as a natural additive in foods. Trends Food Sci. Technol. 2021, 115, 380-390. [CrossRef]

38. Leontopoulos, S.V.; Giavasis, I.; Petrotos, K.; Kokkora, M.; Makridis, C. Effect of different formulations of polyphenolic compounds obtained from OMWW on the growth of several fungal plant and food borne pathogens. Studies in vitro and in vivo. Agric. Agric. Sci. Proced. 2015, 4, 327-337. [CrossRef]

39. Quaglia, M.; Moretti, C.; Cerri, M.; Linoci, G.; Cappelletti, G.; Urbani, S.; Taticchi, A. Effect of extracts of wastewater from olive milling in postharvest treatments of pomegranate fruit decay caused by Penicillium adametzioides. Postharv. Biol. Technol. 2016, 118, 26-34. [CrossRef]

40. Thielmann, J.; Kohnen, S.; Hauser, C. Antimicrobial activity of Olea europaea Linné extracts and their applicability as natural food preservative agents. Int. J. Food Microb. 2017, 251, 48-66. [CrossRef]

41. Ahmed, A.M.; Rabii, N.S.; Garbaj, A.M.; Abolghait, S.K. Antibacterial effect of olive (Olea europaea L.) leaves extract in raw peeled undeveined shrimp (Penaeus semisulcatus). Int. J. Vet. Sci. Med. 2014, 2, 53-56.

42. Polyhealth, S.A. General Description and Technical Characteristics of Medoliva Olive Extract. Available online: https://www. polyhealth.gr/en/proionta/medoliva (accessed on 13 August 2021).

43. Soni, M.G.; Burdock, G.A.; Christian, M.S.; Bitler, C.M.; Crea, R. Safety assessment of aqueous olive pulp extract as an antioxidant or antimicrobial agent in foods. Food Chem. Toxicol. 2006, 44, 903-915. [CrossRef]

44. Serra, A.T.; Matias, A.A.; Nunes, A.V.; Leitão, M.C.; Brito, D.; Bronze, R.; Silva, S.; Pires, A.; Crespo, M.T.; San Romão, M.V.; et al. In vitro evaluation of olive-and grape-based natural extracts as potential preservatives for food. Innov. Food Sci. Emerg. Technol. 2008, 9, 311-319. [CrossRef]

45. Tafesh, A.; Najami, N.; Jadoun, J.; Halahlih, F.; Riepl, H.; Azaizeh, H. Synergistic antibacterial effects of polyphenolic compounds from olive mill wastewater. Evid. Based Complem. Altern. Med. 2011, 2011, 431021. [CrossRef] [PubMed]

46. Khemakhem, I.; Abdelhedi, O.; Trigui, I.; Ayadi, M.A.; Bouaziz, M. Structural, antioxidant and antibacterial activities of polysaccharides extracted from olive leaves. Int. J. Biol. Macromol. 2018, 106, 425-432. [CrossRef] [PubMed]

47. Waterhouse, A.L. Determination of total phenolics. In Current Protocols in Food Analytical Chemistry; Wrolstad, R.E., Ed.; John Wiley and Sons: New York, NY, USA, 2002; pp. I1.1.1-I1.1.8.

48. Hassan, S.M.; Al Aqil, A.A.; Attimarad, M. Determination of crude saponin and total flavonoids content in guar meal. Adv. Med. Plant Res. 2013, 1, 24-28. 